\title{
Use of stable isotopes to assess the intraspecific foraging niche of males and female colour morphs of the damselfly Enallagma hageni
}

\author{
M I CHAEL GR ANT, ${ }^{1}$ ANDREW R O B I S O N ${ }^{1}$ and O L A M . \\ F I N C K E ${ }^{2}{ }^{1}$ University of Michigan Biological Station, Pellston, Michigan, U.S.A. and ${ }^{2}$ Ecology and Evolutionary \\ Biology Program, Department of Biology, University of Oklahoma, Norman, Oklahoma, U.S.A.
}

\begin{abstract}
For the first time, diet and isotopic niche overlap among males and two female-specific colour morphs of a damselfly were quantified to test whether sexual conflict could cause intra-sexual diet variation.

2. Relative to the green female morph, blue females, similar in coloration to the blue males, may be more likely overlooked by mate-searching males. If so, blue females should be more likely to forage unmolested at lake shores, where the density of males and prey is high. The blue morph's isotopic niche space should therefore differ from that of green females and be more similar to that of males.

3. Stable isotope analyses of two Michigan populations failed to support these predictions. Despite population differences in $\delta^{13} \mathrm{C}$ and diet, within sites isotopic niches overlapped among males and females, with little difference between the two female colour morphs.

4. Males exhibited the broadest isotopic niche area, which increased across years, whereas that of blue females became more restricted, possibly due to greater sexual harassment in forest feeding sites.

5. There was an unexpectedly high shift in $\delta^{13} \mathrm{C}$ from prey to predator. Future work is merited to determine whether such trophic shifts are characteristic of Odonata, a group of important aquatic and terrestrial predators.
\end{abstract}

Key words. Colour polymorphism, diet breadth, Odonata, sexual conflict, trophic shift.

\section{Introduction}

Intraspecific variation in foraging niches, known particularly from vertebrates, may result from intraspecific competition for food among adults (Johnson, 1986; Ehlinger \& Wilson, 1988; Schluter, 1993; Alanärä et al., 2001) or between juveniles and adults (Marrin, 1983; Chizinski et al., 2007). Additionally, intraspecific niche partitioning can evolve as one consequence of sexual dimorphism in body size (Shine et al., 2002; Lewis et al., 2006) or other morphologies (Smith, 1990). The result of such niche partitioning is usually variation in dietary overlap within a species.

Although dietary overlap has historically been calculated by direct methods such as analysis of gut contents, increasingly,

Correspondence: Ola M. Fincke, Ecology and Evolutionary Biology Program, Department of Biology, University of Oklahoma, Norman, OK 73019, U.S.A. E-mail: fincke@ou.edu analysis of stable isotopes of carbon and nitrogen are used to determine diet preferences and/or habitat use (Fry et al., 1978; Herrera et al., 2008; Layman et al., 2012). A major advantage of isotope analysis is that it provides a direct measure of food assimilated as opposed to food only recently ingested. An organism's niche space can be represented using stable isotope ratios as axes because energy flow is closely linked to carbon isotope ratios and trophic position to nitrogen isotope ratios (Bolnick et al., 2003; Bearhop et al., 2004). The $\delta^{13} \mathrm{C}$ ratios reflect the basal resource in food webs and are thought to be fairly constant across trophic levels. On the other hand, $\delta^{15} \mathrm{~N}$ ratios indicate trophic position and are expected to be more enriched in the heavier isotope in predators, relative to their prey (Deniro \& Epstein, 1981; McCutchan et al., 2003). The resulting $\delta$-space should be strongly correlated with the ecological niche space described by Hutchinson (1978) because both carbon and nitrogen ratios are conditional upon 
local environmental conditions (Newsome et al., 2007). Using intra-population variation in isotopic signatures, ecologists have begun to re-examine individual specialisation, population dynamics and niche breadth (Bolnick et al., 2003; Bearhop et al., 2004; Kelly et al., 2004; Matthews \& Mazumder, 2004; Layman et al., 2012).

Here, we use stable isotopes to estimate diet and trophic niche space to test, for the first time, the possibility of intraspecific partitioning of the foraging niches among male damselflies and their colour-polymorphic females. Like many insects, damselflies are typically sexually dimorphic in size; males are often slightly smaller than females (Westfall \& May, 1996). Our primary interest here, however, lies not in the effects that sexual dimorphism may have on diet per se, but rather in determining possible dietary consequences of the female-specific colour polymorphism, which occurs in over 100 species of Holarctic odonates (reviewed by Fincke et al., 2005). Females of our study species, Enallagma hageni Walsh, exhibit two distinct colour morphs: a blue morph that is similar to the blue male in coloration and a green morph whose colour reflectance differs from that of the male (Fincke et al., 2007). Female body coloration and pattern are known to be a Mendelian trait in Ischnura, the sister genus to Enallagma, as well as in Coenagrion (reviewed by Van Gossum et al., 2008). We thus assume that similar genetics control the polymorphism in Enallagma.

Female-specific colour polymorphism is a common characteristic of damselflies in the family Coenagrionidae, whose non-territorial males must search for mates, often in multiple microhabitats, such as forests, fields and lake shores, where feeding also occurs. For damselfly species with mate-searching males, female colour variation has long been suspected to result in part from sexual conflict over mating rates. Specifically, the polymorphism has been considered an evolutionary response by females to reduce male harassment, although specific hypotheses differ in details (reviewed by Fincke, 2004; Van Gossum et al., 2008). Of interest here is the fact that, because of their signal similarity to the blue males, blue females, typically viewed as sexual mimics, may frequent areas occupied by males without being as readily detected by males as potential mates, and hence enjoy lower harassment from males compared with the green females (Robertson, 1985; Sherratt, 2001). For example, Forbes et al. (1995) found that, at high-density sites, male-like female Nehalennia were more likely than green females to frequent lake shore areas. At the edges of these aquatic habitats, emerging insect prey is abundant, and males are often seen foraging there. Hence, if blue females indeed frequent a different feeding microhabitat from that of green females and, more specifically, forage in areas frequented by males, one would predict, respectively, that (i) the diets of blue and green females will differ, and (ii) relative to the trophic niche of green females, that of blue females should be more similar to that of males. We tested these hypotheses about adult diets in two different populations of Enallagma hageni in northern Michigan. Our results failed to support either hypothesis, but revealed a more complex picture of diet breadth than we expected.

\section{Materials and methods}

\section{Study species and populations}

Like all odonates (Corbet, 1999), our study species, E. hageni is a predator as both an aquatic larva and as an adult. Newly emerged 'teneral' adults are opaque in colour and typically take a day for the cuticle to harden, after which they begin feeding on small flying insects. Thus, the isotopic signature of newly emerged adults reflects their diet as aquatic larvae. During the week or so needed to reach sexual maturity, adults rapidly increase in body mass (Anholt et al., 1991). Enallagma males are often observed feeding in the grassy areas along lake shores, where the density of males searching for mates and hence the operational sex ratio is high (Fincke, 1982, 1994). Between bouts of mating and oviposition at the water's edge, females and most males at our study sites returned to the forest where both sexes were observed feeding in forest light gaps (Fincke, 1986a; O. M. Fincke, unpublished).

Our study was conducted at two sites in northern Michigan during the summers of 2010, 2011 and 2012. Populations at both sites produced only one generation per year, with adults flying from mid-June to early August. The Sugar Island (SI) population in the eastern Upper Peninsula of Michigan was located in the Chase Osborn Preserve $\left(46.4^{\circ} \mathrm{N}\right.$, $84.2^{\circ} \mathrm{W}$ ) in Chippewa County. Here, adult E. hageni bred on Duck Lake and the contiguous Sweet Gale Lake, both of which are connected to the St Marys River. Based on water samples taken during our study, these two water bodies were only slightly alkaline (41-44 $\mathrm{mg} \mathrm{CaCO}_{3} \mathrm{l}^{-1}$ ) but had a relatively high concentration of dissolved organic carbon (DOC, 11-15 mg C $1^{-1}$ ). The macrophyte community consisted of Najas flexilis, Vallisneria sp. and Elodea sp. Emergent vegetation was dominated by Carex stricta, Scripus acutus and Dulichium arundinaceum. Close to shore was a shrubby zone of blueberry (Vaccinium sp.) and Myica gale. Most of the terrestrial habitat was conifer and mixed hardwood forest that was roughly $10-20 \mathrm{~m}$ from the water's edge.

The second study population bred on Larks Lake (LL, $45.6^{\circ} \mathrm{N}, 84.9^{\circ} \mathrm{W}$ ) located in Emmet County, Michigan, roughly $143 \mathrm{~km}$ south of the SI population. Larks is a shallow alkaline lake (114-116 mg $\mathrm{CaCO}_{3} \mathrm{l}^{-1}$ with a DOC of $7-8 \mathrm{mg} \mathrm{Cl}^{-1}$ at the time of our study). The substrate consisted of a sandy bottom, which supports a limited array of aquatic vegetation. Typical submerged vegetation included Najas flexilis, Chara sp. and the filamentous green alga Spirogyra sp. Emergent vegetation included Scirpus americanus and S. acutus. The shoreline consisted of a shrubby zone which graded into a mixed conifer-hardwood forest, about 5-10 $\mathrm{m}$ from the waterline.

\section{Collection of damselflies}

To standardise the reproductive condition of sexually mature adults, tandem pairs (i.e. females clasped by males prior to copula) were collected along the water's edge using an insect net. Two sample sets were taken from each site during each study year, one early in the reproductive season and another about 2 weeks later (total $N=267$ sexually mature adults). 
To calculate the approximate time needed for damselfly tissue to equilibrate with its diet as an adult, females from the LL population were sorted by age group. We used the presence of ectoparasitic water mites and the scars they leave as evidence of the relative age of females (i.e. younger and older damselflies, respectively). The mites attach to the venter of a damselfly's abdomen during its emergence from the final-instar larva (Smith, 1988), which occurs on emergent vegetation. The mites feed on their host and then detach from the damselfly when it returns to the water to breed and females submerge to lay eggs (Fincke, 1986b; Rolff \& Martens, 1997). After detachment, a scar remains on the damselfly's abdomen, evidence that the adult has had one or more bouts of breeding. Additionally, because the wax that adults secrete on their bodies accumulates over time, we scored a female as relatively old if she had a very waxy (i.e. whitish) abdomen or exhibited extreme wing wear. We grouped individuals into four categories of relative age as follows: 0 , tenerals; 1 , young mature (i.e. with mites; $>5$ and $<10$ days old); 2 , older mature adults (i.e. with scars of mites, 1.5-3 weeks old); and 3, old adults (with whitish abdomens, $\geq 3$ weeks old).

\section{Availability of potential prey}

We assessed the relative abundance and microhabitat distribution of suitably small, flying prey at both study sites by placing sticky fly paper strips in the field in mid-season. Sticky traps were placed along the shore within $10 \mathrm{~m}$ of the water's edge, and at different small light gaps in the forest where damselflies were observed to feed. Traps were left in the field for $24 \mathrm{~h}$ of clear weather and then returned to the laboratory where trapped insects were identified to family and their relative distribution determined.

\section{Isotope analyses of damselfly predators and their potential prey}

Live adult E. hageni were held in small glassine envelopes under cool conditions for transport to the laboratory where they were then frozen at $-80^{\circ} \mathrm{C}$ until analysed. Samples were dried in a lyophiliser until reaching a constant weight. After drying they were kept in a tightly closed container and stored in a freezer until further processing. Specimens did not appear to discolour during storage. Only the thorax, cut into quarters, was used for isotopic measurement, except in 2010 when the abdomen was also used. Lipids were not removed prior to isotopic analysis because the molar $\mathrm{C}: \mathrm{N}$ ratio for all adults was consistently low, ranging from 4.36 to 5.71, suggesting a minimal effect of fat on our results. To test whether inorganic carbonates might be affecting the organic carbon signal, a subset of damselfly adults was treated with dilute $\mathrm{HCl}(1 \mathrm{M})$ overnight and then redried. The carbon signal before and after acid treatment showed no statistical difference (data available upon request).

For carbon and nitrogen analyses, approximately $0.4 \mathrm{mg}$ of sample was weighed into a tin capsule $(5 \times 9 \mathrm{~mm})$ and placed in a Costech 4010 Elemental Analyzer (Costech Analytical
Technologies Inc., Valencia, California), which was coupled to a Thermo Finnigan Delta Plus XP mass spectrometer (Thermo Electron Corp., San Jose, California). During each run, standards were placed after every 10 samples to correct for instrumental drift. All results are expressed using the $\delta$ notation, with units expressed in per mil fashion. The reference materials were secondary standards previously calibrated against international standards. Carbon results are reported relative to Vienna PeeDee Belemnite (VPDB) and nitrogen relative to atmospheric $\mathrm{N}_{2}$. In addition to standards, a control sample (caffeine) was analysed with every run throughout the study period and used to estimate instrumental precision. Nitrogen control values had a precision of $\pm 0.2 \%$, while carbon was $\pm 0.1 \%$. Because our measures were at odds with some in the literature (see the Discussion section), we had another laboratory measure 13 of our individuals. Those results were no different from ours, and thus were included in the analyses.

Suitable damselfly prey were collected with insect nets from each site, identified to family, then dried, ground and analysed for $\delta^{15} \mathrm{~N}$ and $\delta^{13} \mathrm{C}$ as described earlier. To estimate variability of isotopic signatures of prey, individual prey items were analysed whenever possible; otherwise they were pooled to achieve sufficient mass for analysis. Although several types of chironomid species were analysed, we failed to sample Chironomus anthracinus and Chironomus plumosus, both of which are known from the study sites. These species of chironomid typically inhabit deeper waters and consume methanotrophic bacteria, resulting in very depleted ${ }^{13} \mathrm{C}$ isotope signals. We included them as possible prey items, using the average carbon and nitrogen values obtained from the literature (Hecky \& Hesslein, 1995; Grey et al., 2004; Kelly et al., 2004). The prey data were used to construct biplots of isotopic signatures of damselfly predators and their potential prey.

\section{Analysis of trophic enrichment and foraging niche space}

Before one can assess the diet of a predator, it is necessary to determine the trophic shift (i.e enrichment) that occurs as carbon and nitrogen move up the food chain. Trophic enrichment $\Delta$ is defined as $\delta \mathrm{X}_{\text {consumer }}-\delta \mathrm{X}_{\text {diet }}$, where $\mathrm{X}$ represents either the carbon or nitrogen isotopic signal. The variance $v(\Delta)$ can be calculated from the equation: $v(\Delta)=\left(n^{\mathrm{f}}-1\right)\left(s^{\mathrm{f}}\right)^{2}+\left(n^{\mathrm{c}}-1\right)\left(s^{\mathrm{c}}\right)^{2} /\left(n^{\mathrm{f}}+n^{\mathrm{c}}-2\right)$, where $n^{\mathrm{f}}$ and $n^{\mathrm{c}}$ are sample sizes of the food and consumer, and $\left(s^{\mathrm{f}}\right)^{2}$ and $\left(s^{\mathrm{c}}\right)^{2}$ are the variances for the food and consumer, respectively (Hedges \& Olkin, 1985). Trophic enrichment was determined using $25 \mathrm{SI}$ females that had been collected as tenerals and held in a flight cage until sexual maturation (5-8 days). These were fed ad libitum on a diet of mosquitoes (Culex sp.) collected on-site. The females were subsequently harvested and their thoraxes as well as a sample of 24 mosquitoes were analysed for $\delta^{13} \mathrm{C}$ and $\delta^{15} \mathrm{~N}$ as described earlier.

In order to reconstruct the diet of adult damselflies, we corrected the isotopic signal of the adults for trophic enrichment by subtracting the trophic enrichment factor calculated earlier. The resource proportions in the diet of $E$. 
Table 1. Mean \pm SD of isotope results for Enallagma hageni adults on Sugar Island (SI) and Larks Lake (LL), 2010-2012 (ranges in parentheses).

\begin{tabular}{llllll}
\hline Site & Year & Group & $\mathrm{N}$ & $\delta^{13} \mathrm{C}(\% \circ)$ & $\delta^{15} \mathrm{~N}(\% \circ)$ \\
\hline SI & 2010 & $\mathrm{M}$ & 24 & $-25.38 \pm 1.70(-29.18$ to -21.36$)$ & $2.3 \pm 0.4(1.7-3.0)$ \\
SI & 2010 & BF & 12 & $-24.68 \pm 1.29(-26.72$ to -22.77$)$ & $2.1 \pm 0.4(1.2-3.0)$ \\
SI & 2010 & GF & 11 & $-24.93 \pm 0.64(-25.84$ to -23.70$)$ & $2.9 \pm 0.7(2.0-4.2)$ \\
SI & 2011 & Teneral & 17 & $-27.63 \pm 0.62(-29.05$ to -26.32$)$ & $3.0 \pm 0.3(2.6-3.8)$ \\
SI & 2011 & M & 37 & $-27.01 \pm 2.06(-30.23$ to -23.20$)$ & $3.7 \pm 0.6(2.3-5.1)$ \\
SI & 2011 & BF & 27 & $-27.59 \pm 1.30(-29.46$ to -24.32$)$ & $3.8 \pm 0.5(2.9-4.9)$ \\
SI & 2011 & GF & 25 & $-26.97 \pm 1.90(-29.39$ to -21.92$)$ & $3.6 \pm 0.7(2.3-4.8)$ \\
SI & 2012 & M & 11 & $-26.77 \pm 2.18(-29.05$ to -22.24$)$ & $3.7 \pm 0.8(2.3-5.7)$ \\
SI & 2012 & BF & 10 & $-24.89 \pm 0.87(-26.75$ to -24.14$)$ & $3.7 \pm 0.3(3.3-4.2)$ \\
SI & 2012 & GF & 11 & $-24.34 \pm 1.57(-26.45$ to -20.50$)$ & $4.0 \pm 0.5(3.1-5.2)$ \\
LL & 2011 & Teneral & 4 & $-21.57 \pm 1.1(-22.80$ to -20.57$)$ & $3.2 \pm 0.5(2.7-3.8)$ \\
LL & 2011 & M & 33 & $-23.45 \pm 0.80(-25.22$ to -22.21$)$ & $4.3 \pm 0.7(3.3-5.8)$ \\
LL & 2011 & BF & 26 & $-24.38 \pm 0.95(-26.17$ to -22.67$)$ & $4.2 \pm 0.5(3.1-5.5)$ \\
LL & 2011 & GF & 40 & $-24.02 \pm 0.96(-26.47$ to -21.84$)$ & $4.0 \pm 0.7(2.4-5.4)$ \\
\hline
\end{tabular}

$\mathrm{M}$, male; BF, blue female; GF, green female.

hageni adults were calculated using ISOSOURCE (Philips \& Gregg, 2003), a computer program available online which calculates likely mixing proportions satisfying the isotopic mass balance equation of the predator, as follows:

$$
\delta \mathrm{X}_{\text {predator }}=\left(\mathrm{f}_{\mathrm{a}}\right)\left(\delta \mathrm{X}_{\mathrm{a}}\right)+\left(\mathrm{f}_{\mathrm{b}}\right)\left(\delta \mathrm{X}_{\mathrm{b}}\right)+\left(\mathrm{f}_{\mathrm{n}}\right)\left(\delta \mathrm{X}_{\mathrm{n}}\right)
$$

where $X$ is the carbon or nitrogen isotopic signal of the predator, $f$ is the proportion of resource contributing to mix, and $X_{\mathrm{n}}$ is the isotopic signal of resource.

Because the number of possible prey contributing to the mix exceeded $n+1$ isotopes measured, an exact solution to the mixing problem was not possible; instead ISOSOURCE returned a range of solutions satisfying the mass balance equation. In order to better constrain the model (reduce the number of possible prey classes), we averaged the isotopic signals of trichoptera and emphemeroptera (aquatic resource) and homoptera (plant hoppers), lepidoptera and coleoptera (terrestrial resource). We accepted solutions to the mixing problem that were $\leq 0.02 \%$ different from the average predator signal.

Additionally, we calculated the trophic niche area for males and each female colour morph for the SI population for three consecutive breeding seasons (2010-2012), using Bayesian inference techniques (after Jackson et al., 2011). The total area of the resulting ellipses, an indirect measure of trophic niche space, is based on $\delta^{15} \mathrm{~N}$ of the individuals in each of the three groups (i.e. males plus the two female colour morphs), corrected for sample size. The areas were bootstrapped ( $n=10000)$ to account for natural variations in the data set. The metrics were calculated using the download package SIBER (Stable Isotope Bayesian Ellipses in R) which is part of the Stable Isotope Analysis for the $\mathrm{R}$ statistical environment. The corrected ellipse area was thus less sensitive to sample size, and provides confidence intervals around the means, in lieu of comparator statistics, which remain a challenge. Bayesian inference has the added advantage of generating a range of probable values for the calculated areas, whose confidence intervals can be calculated, an improvement on a metric describing niche width developed by Layman et al. (2007).

\section{Statistical analyses}

Because diets differed between the two populations, analyses were done by population. A few of the isotopic data sets were not normally distributed in some years, even after log transformation. Hence non-parametric Krusksl-Wallis tests (NPAR1WAY in SAS, version 9.2) were used to analyse the isotopic data. Analysing the normally distributed isotopic data with parametric tests did not change any of our conclusions. General linear models (GLM, SAS) were used for all other data (i.e. determined to be normally distributed using Shapiro-Wilk tests). Throughout, means are given \pm SD.

\section{Results}

Isotopic signatures of $\mathrm{E}$. hageni predators

Table 1 summarizes isotope data from the two study populations of E. hageni. There was no difference between male and female tenerals in $\delta^{13} \mathrm{C}(H=1.03,1$ d.f., $P=0.31)$ or $\delta^{15} \mathrm{~N}(H=0.00,1$ d.f., $P=1.0)$. Tenerals from SI were more depleted in $\delta^{13} \mathrm{C}$ relative to those at $\mathrm{LL}(H=9.27$, 1 d.f., $P<0.002)$, although there was no difference in $\delta^{15} \mathrm{~N}$ ( $H=0.08,1$ d.f., $P=0.93$ ). There was no difference between the $\delta^{13} \mathrm{C}$ signal of tenerals and adults at the SI site $(H=0.48$, 1 d.f., $P=0.83)$, but at $\mathrm{LL}$, tenerals were more enriched than the adults $(H=10.08,1$ d.f., $P<0.001)$. At both sites, tenerals were depleted in $\delta^{15} \mathrm{~N}$ relative to adults $(H=20.82$, 1 d.f., $P<0.001$ and $H=6.75,1$ d.f., $P=0.01$ for SI and LL, respectively). As shown in Fig. 1, newly emerged teneral $E$. hageni reached equilibrium with their diet as terrestrial adults within a week or less of emergence.

Among sexually mature adults on SI, there were year-toyear differences in $\delta^{13} \mathrm{C}(H=42.30,2$ d.f., $P<0.0001)$ and $\delta^{15} \mathrm{~N}(H=80.80,2$ d.f., $P<0.0001)$. Thus, only 2011 data 

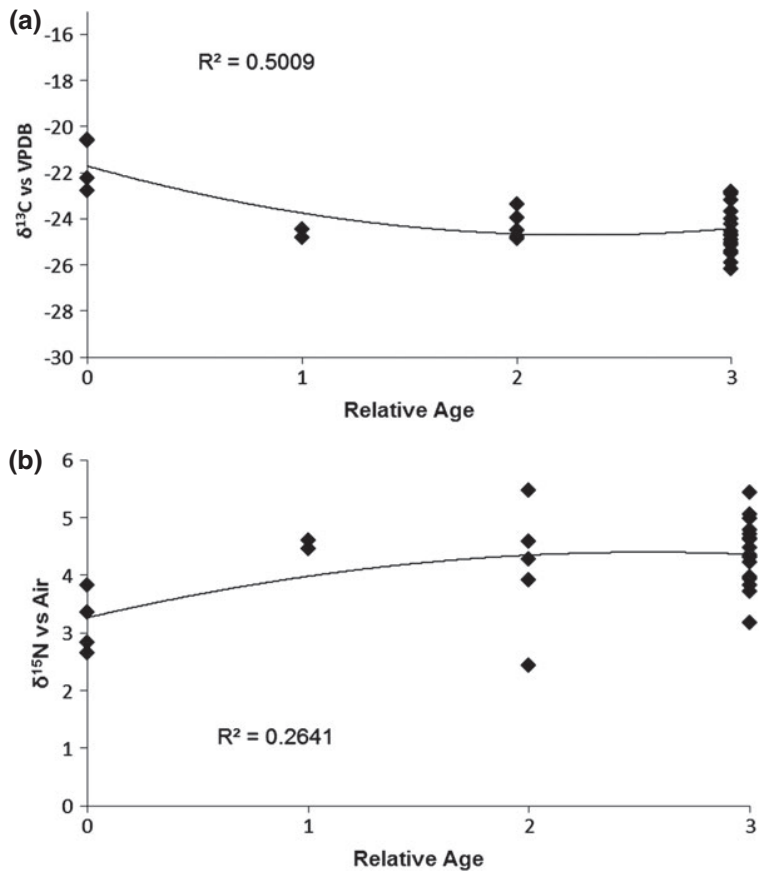

Fig. 1. Isotopic shift with relative age of Larks Lake females: (a) $\delta^{13} \mathrm{C}$; (b) $\delta^{15} \mathrm{~N}$. Age class $=0$ refers to newly emerged tenerals, which should reflect the larval diet. See text for description of relative ages.

were used for comparison of the two study sites. Compared with LL, adults on SI were more depleted in $\delta^{13} \mathrm{C}(H=93.86$, 1 d.f., $P<0.0001)$ and $\delta^{15} \mathrm{~N}(H=23.01,1 \mathrm{df}, P<0.0001)$. In the SI population pooled across years, there was no difference in the isotopic signatures between the two female colour morphs in $\delta^{13} \mathrm{C}(H=2.15,1$ d.f., $P=0.34)$ or $\delta^{15} \mathrm{~N}$ ( $H=2.95$, 1 d.f., $P=0.23$ ), or between males and females (for $\delta^{13} \mathrm{C}: H=1.24$, 1 d.f., $P=0.26$; for $\delta^{15} \mathrm{~N}$ : $H=2.54$, 1 d.f., $P=0.11)$. Similarly, in the $\mathrm{LL}$ population, neither $\delta^{13} \mathrm{C}(H=2.03,1$ d.f., $P=0.15)$ nor $\delta^{15} \mathrm{~N}(H=3.63$, 1 d.f., $P=0.06)$ differed between the female morphs. However, compared with males, females were more depleted in $\delta^{13} \mathrm{C}$ ( $H=12.54$, 1 d.f., $P=0.0004)$, whereas the sexes did not differ in $\delta^{15} \mathrm{~N}(H=0.86,1$ d.f., $P=0.35)$.

\section{Availability of potential prey}

The data on the small prey caught in the sticky traps are summarized in Table 2. There was no difference in total number of suitable small prey items between the two study sites $\left(F_{1,5}=1.26, P=0.36\right)$, or between the shore and the forest locations $\left(F_{1,5}=0.04, P=0.84\right)$, and no interaction effects. At both sites small diptera, particularly midges and phorid flies, were the most abundant prey. LL had more leafhoppers and other hompterans than did the SI site $\left(F_{1,5}=8.67, P=0.03\right)$. Finally, at both sites, more Tricoptera $\left(F_{1,5}=6.98, P=0.045\right)$ and Lepidoptera $\left(F_{1,5}=6.64, P=0.05\right)$ occurred near the shore than in the forest.

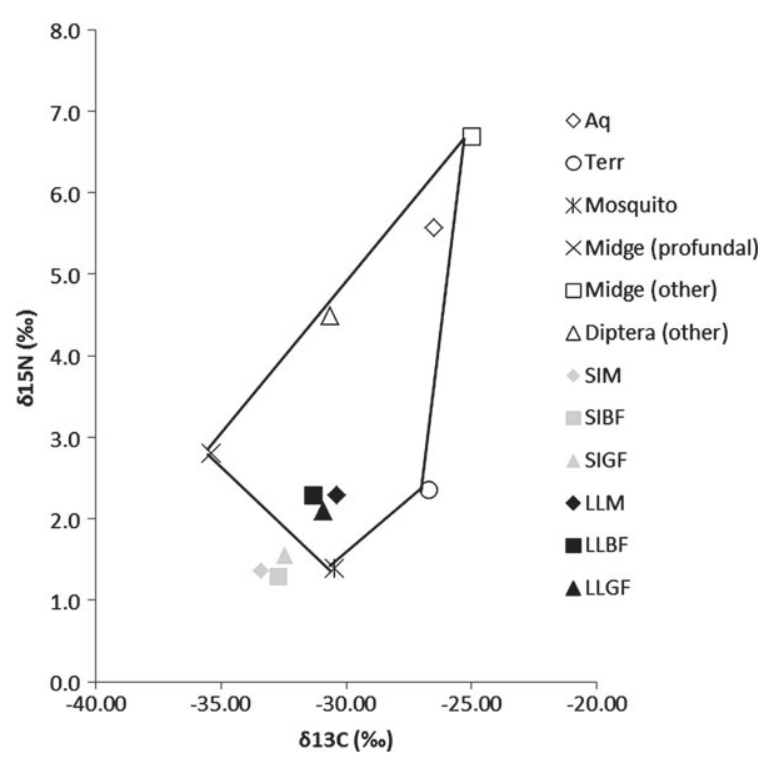

Fig. 2. Bi-plot of predator types from Larks Lake (LL) and Sugar Island (SI) and the prey mixing model. M, male; BF, blue female; $\mathrm{GF}$, green female. Sample sizes for damselflies are in Table 1; for prey, see Table 3 .

\section{Isotopic niche space of predators and their potential prey}

The mean enrichment of $\delta^{13} \mathrm{C}$ from prey to predator was $6.9 \pm 1.3 \%$, the difference between the mean $\delta^{13} \mathrm{C}$ of 25 damselflies $(-23.58 \pm 1.9)$ and that of the mosquito prey on which they were raised $(-30.50 \pm 1.6, n=24)$. The mean $\delta^{15} \mathrm{~N}$ enrichment value was $1.9 \pm 1.1 \%$, the difference between the mean $\delta^{15} \mathrm{~N}$ of the 25 damselflies $(3.3 \pm 0.72)$ and that of the 24 mosquito prey $(1.4 \pm 1.1)$. Figure 2 shows the bi-plot of predator types from both populations, corrected for the above trophic shift, and the prey mixing model. We were unable to model the diet from the SI site because the predator signal fell outside the mixing polygon, indicating that a possible prey item was missing from our data set (Table 3). It should be noted however, that the predator signal fell very close to the edge of the mosquito-profundal midge contour, suggesting that these items probably played a significant role in the diet of the SI population. The LL population fed heavily on mosquitoes $(50-60 \%)$ followed by midges (profundal) $(15-30 \%)$ and terrestrial insects $(8-12 \%)$ along with lesser amounts of other items (Table 4).

A summary of the average ellipse area for each colour morph is shown in Fig. 3. Whereas the ellipse areas of the male and female colour morphs in 2010 did not vary greatly in either population, by 2012 blue females in the SI population appeared to utilise a smaller niche area, while green females and males, in particular, enlarged their niche space. Figure 4 shows the density plots of the confidence intervals of the standard ellipse areas; the niche space of males expanded, whereas that of the blue females contracted over the 3-year study of the SI population. 
Table 2. Mean \pm SD of small prey caught in sticky traps on shore and in forest light gaps at each study site $(n=2$ traps per location per site; eight in total).

\begin{tabular}{|c|c|c|c|c|c|}
\hline Location/site & Total & Diptera & Tricoptera & Lepidoptera & Homoptera \\
\hline \multicolumn{6}{|l|}{ Larks Lake } \\
\hline Shore & $97.0 \pm 31.11$ & $81.50 \pm 29.00$ & $5.5 \pm 3.54$ & $4.0 \pm 1.41$ & $1.0 \pm 0$ \\
\hline Forest & $83.5 \pm 13.43$ & $70.00 \pm 14.12$ & $2.00 \pm 1.41$ & $1.50 \pm 0.70$ & $1.0 \pm 0$ \\
\hline \multicolumn{6}{|l|}{ Sugar Island } \\
\hline Shore & $50.0 \pm 8.49$ & $36.00 \pm 8.49$ & $7.00 \pm 2.82$ & $1.50 \pm 0.70$ & $1.50 \pm 0.71$ \\
\hline Forest & $74.0 \pm 66.47$ & $70.00 \pm 68.59$ & $1.50 \pm 2.12$ & $1.50 \pm 2.12$ & $0.50 \pm 0.71$ \\
\hline
\end{tabular}
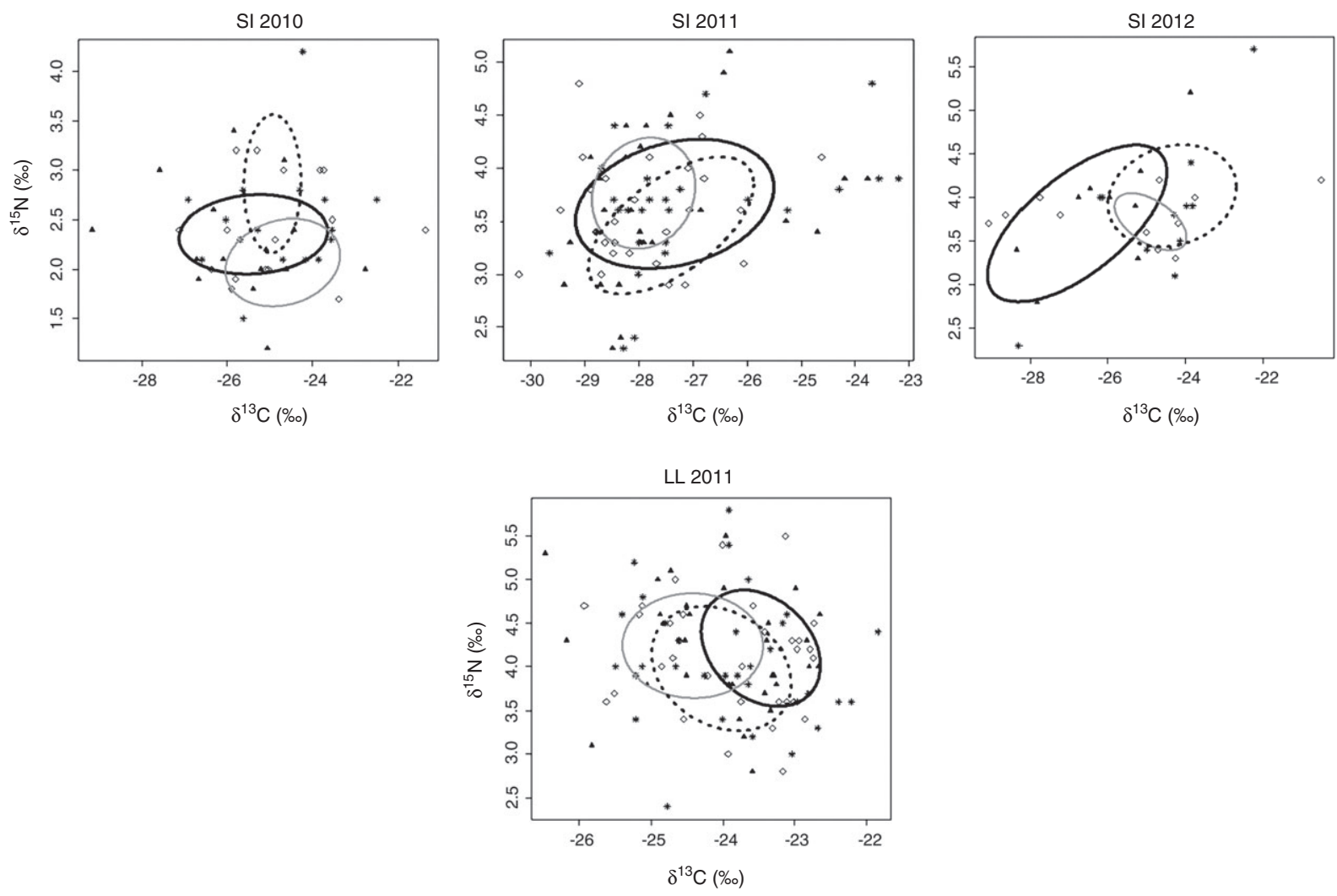

Fig. 3. Standard ellipse areas for Enallagma hageni male (black), blue female (gray) and green female (dotted) for Sugar Island (SI), 2010-2012, and Larks Lake (LL, 2011 only). The standard ellipse area represents the central 45\% of the data in each set.

\section{Discussion}

Before reaching sexual maturity, adult E. hageni had equilibrated to their terrestrial diet (Fig. 1). This is similar to the time of 5-8 days required for laboratory-reared locusts to equilibrate (Webb et al., 1998). Newly emerged E. hageni at LL (but not on SI) had an enriched ${ }^{13} \mathrm{C}$ signal, reflecting their aquatic prey, which would derive most of their energy indirectly from carbonates dissolved in the water (i.e. a resource much higher in LL relative to SI). Adult diets differed slightly but significantly between the two Michigan populations, but at both sites E. hageni fed at the same trophic level as indicated by similar ${ }^{15} \mathrm{~N}$ values. Although the two populations differed significantly in their prey base, the isotopic signatures across the sexes and colour morphs at each site were remarkably consistent (Table 1). Mosquitoes seemed to dominate the diet of the LL population, while the SI population was probably influenced by a prey item highly depleted in ${ }^{13} \mathrm{C}$, as indicated by its downfield shift from the LL population (Fig. 2). Small diptera dominated our samples of available prey at both sites, accounting for $72-95 \%$ of available prey caught in the sticky traps (Table 2). Surprisingly, prey abundance wasn't greater near the shore than in the forest, probably because in the latter, sampling was done only in light gaps where damselflies foraged. Nevertheless, it suggests that females may not be paying an increased cost in foraging efficiency by remaining away from the water while unreceptive to mating.

For each study population, our results did not reveal significant differences between the diets of blue and green 
Table 3. Mean $\pm \mathrm{SD}$ of nitrogen and carbon isotope ratios for representative prey items.

\begin{tabular}{llll}
\hline Sample & $N$ & $\delta^{13} \mathrm{C} \pm \mathrm{SD}$ & $\delta^{15} \mathrm{~N} \pm \mathrm{SD}$ \\
\hline Mosquito & 14 & $-30.50 \pm 1.6$ & $1.7 \pm 1.6$ \\
Lepidoptera & 4 & $-25.21 \pm 2.1$ & $2.6 \pm 1.8$ \\
Trichoptera & 7 & $-25.93 \pm 2.5$ & $5.5 \pm 0.9$ \\
Emphemeroptera & 5 & $-28.56 \pm 4.0$ & $4.5 \pm 0.5$ \\
Midge (profundal) & - & -35.38 & 2.8 \\
Midge (other) & 6 & $-25.02 \pm 1.0$ & $6.7 \pm 1.3$ \\
Homoptera (plant hopper) & 6 & $-28.23 \pm 0.9$ & $0.4 \pm 2.3$ \\
Diptera (other) & 3 & $-30.65 \pm 0.14$ & $4.5 \pm 2.3$ \\
Coleoptera & 4 & $-26.77 \pm 2.3$ & $4.1 \pm 0.6$ \\
\hline
\end{tabular}

*Mean literature values (see text).

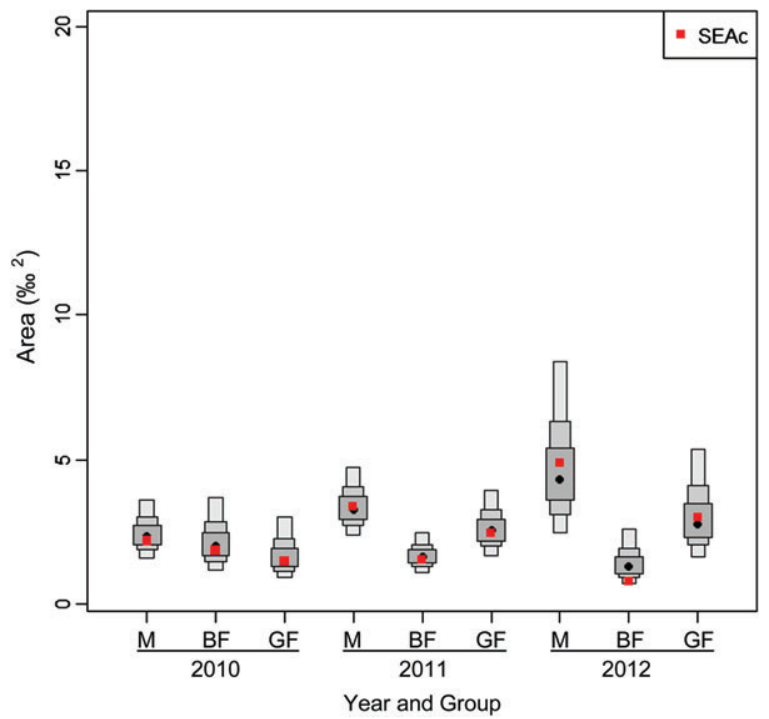

Fig. 4. Density plots showing the confidence intervals of the standard ellipse areas for Enallagma hageni populations on Sugar Island (3 years) and Larks Lake (1 year). SEAc (corrected for small sample size $)=\mathrm{SEA} \times(n-1) /(n-2)$. The box areas reflect the $95 \%, 75 \%$ and $50 \%$ confidence areas. $\mathrm{M}$, male; BF, blue female; GF, green female.

females, suggesting that the two morphs foraged on similar prey (Fig. 2). This was contrary to expectations if blue females were more likely than green ones to forage in the same areas as males, which foraged at the water as well as in forests. The latter assumes that the isotopic signatures of actual damselfly prey differs between shoreline and forest. It's possible that regardless of where they forage, damselflies select similar prey even though foraging efficiency may differ between locations.

Nevertheless, compared with the blue morph, green females were consistently more similar to males in having a relatively broad isotopic niche space compared with blue females (Figs 3 and 4). The ellipse area reflects the isotopic variance among individuals and hence incorporates the breadth of prey taken weighted by their abundance. Males had the largest ellipse areas overall, suggesting that they had the most variable diet, whereas females exhibited less variation in their isotopic signal and generally smaller ellipse areas. This is consistent with other results based on direct observations of feeding adults. Males fed as mature adults on the shore as well as in the forest, whereas females of both colour morphs fed primarily in forest light gaps (O. M. Fincke, unpublished). Similarly, in an earlier study of Enallagma civile, although there was a tendency for blue females to frequent areas closer to shore than green females, the difference was not significant (Miller \& Fincke, 1999). By contrast, Forbes et al. (1995) found that, relative to green females, in five of seven samples at highdensity sites, more male-like blue females of Nehalennia irene were close to shore. Such habitat partitioning has also been seen in Ischnura verticalis, a sister genus to Enallagma, but in developmental colour morphs. The orange and black, sexually immature females feed in areas away from the sexually mature, gray-blue females (Fincke, 1987).

Surprisingly, across the three summers in the SI population, there was a general trend of increasing ellipse area among males that was roughly paralleled by that of the green females, whereas the ellipse area of the blue morph seemed to decrease over the same time (Figs 3 and 4). Because all females were collected in tandem at the breeding site, there is no reason to suspect that such differences reflected age differences among the morphs. Although diets were similar for both sexes and morphs (Fig. 2), the changing ellipse area most likely reflects a change in the variety of prey eaten. Although a lower mosquito density in 2012, a particularly dry year, may account for the unusually variable isotope area, particularly of males, it is unlikely to account for the contraction of the trophic niche of blue females. A second possible cause of a reduced foraging niche of the blue female morph might be greater sexual harassment by males, which increases with blue morph frequency (Xu \& Fincke, 2011). However, the frequency of blue females was lower in 2012 than in 2011 (O. M. Fincke, unpublished). Interestingly, because blue females were found to be harassed more in the forest relative to the shore $(\mathrm{O}$. M. Fincke, unpublished), if population size and thus male harassment were relatively higher there in 2012, blue females might have responded by narrowing their foraging niche space, by avoiding large light gaps frequented by males. Regardless of the cause of the trends, confidence intervals around the ellipses (Fig. 4) strongly suggest that males and their polymorphic females varied in their trophic niches across years on SI (the only population for which we collected data in multiple years).

Although trophic enrichment from prey to predator is known to be quite variable, in a review of the literature, McCutchan et al. (2003) suggested that consumers are enriched by about $2.3 \pm 0.18 \%$ in ${ }^{15} \mathrm{~N}$ and $0.5 \pm 0.13 \%$ in ${ }^{13} \mathrm{C}$. In our study, the ${ }^{15} \mathrm{~N}$ enrichment factor was similar, whereas our mean carbon enrichment $(6.9 \%$ ) was much higher than those in the literature to date. The primary pathway for carbon loss is through respiration and therefore we speculate that odonates may exhibit an unusual respiration pattern, resulting in a largerthan-expected isotopic enrichment. Chapman (1998) points out that the metabolic rate of insects in flight is often 50-100 times larger than when at rest. In actively flying insects, the $\mathrm{O}_{2}$ demand of flight muscles greatly exceeds all other tissues, which may explain the unexpectedly large carbon trophic shift that we found in E. hageni. Respiratory $\mathrm{CO}_{2}$ is depleted in 
Table 4. Source contribution (\%) to Enallagma hageni diet at Larks Lake (LL). The Sugar Island population fell outside of mixing polygon so no solutions could be calculated.

\begin{tabular}{|c|c|c|c|c|c|c|c|c|c|c|c|c|}
\hline \multirow[b]{2}{*}{ ID } & \multicolumn{2}{|c|}{ Aquatic (pooled) } & \multicolumn{2}{|c|}{ Terrestrial (pooled) } & \multicolumn{2}{|c|}{ Mosquito } & \multicolumn{2}{|c|}{ Midge (profundal) } & \multicolumn{2}{|c|}{ Midge (other) } & \multicolumn{2}{|c|}{ Diptera (other) } \\
\hline & Mean & Range & Mean & Range & Mean & Range & Mean & Range & Mean & Range & Mean & Range \\
\hline LLM & 4 & $0-17$ & 12 & $0-45$ & 59 & $23-74$ & 14 & $0-32$ & 3 & $0-13$ & 8 & $0-28$ \\
\hline LLBF & 3 & $0-12$ & 9 & $0-38$ & 52 & $25-63$ & 28 & $16-42$ & 2 & $0-9$ & 6 & $0-22$ \\
\hline LLGF & 3 & $0-11$ & 8 & $0-28$ & 64 & $42-74$ & 19 & $8-30$ & 2 & $0-8$ & 5 & $0-19$ \\
\hline
\end{tabular}

M, male; BF, blue female; GF, green female.

${ }^{13} \mathrm{C}$, resulting in consumers being enriched relative to their diets. This difference should be greatest for animals with high respiration rates (McCutchan et al., 2003). Future work that focuses on isotopic niche space of dragonfly predators is needed to test the generality of the trophic shift in ${ }^{13} \mathrm{C}$ that we found, work that would also more accurately quantify the potential impact these important predators have on their aquatic and terrestrial prey.

\section{Acknowledgements}

We thank Katryn Williams for help in sample preparation, Mark Shields for rearing tenerals, Apolline Auclerc for help with software in R, Paige Blaker for field assistance, Brian Scholtans for help with prey identification, and Jeff F. Kelly for independent confirmation of isotopic values. Two anonymous reviewers provided helpful comments that improved the manuscript. The University of Michigan Biological Station provided logistical support. This research was supported by NSF grant IOS-0641679 to O.M.F.

\section{References}

Alanärä, A., Burns, M.D. \& Metcalfe, N.B. (2001) Intraspecific resource partitioning in brown trout: the temporal distribution of foraging is determined by social rank. Journal of Animal Ecology, 70, 980-986.

Anholt, B.R., Marden, J.H. \& Jenkins, D.M. (1991) Patterns of mass gain and sexual dimorphism in adult dragonflies (Insecta: Odonata). Canadian Journal of Zoology, 69, 1156-1163.

Bearhop, S., Adams, C.E., Waldron, S., Fuller, R.A. \& Macleod, H. (2004) Determining trophic niche width: a novel approach using stable isotope analysis. Journal of Animal Ecology, 73, 1007-1012.

Bolnick, D.I., Svanback, R., Fordyce, J.A., Yang, L.H., Davis, J.M., Hulsey, C.D. et al. (2003) The ecology of individuals: incidence and implications of individual specialization. American Naturalist, 161, $1-28$.

Chapman, R.F. (1998) The Insects: Structure and Function. Cambridge University Press, Cambridge, U.K.

Chizinski, C.J., Huber, C.G., Longoria, M. \& Pope, K.L. (2007) Intraspecific resource partitioning by an opportunistic strategist, inland silverside Menidia beryllina. Journal of Applied Ichthyology, 23, 147-151.

Corbet, P.S. (1999) Dragonflies: Behaviour and Ecology of Odonata. Cornell University Press, Ithaca, New York.

Deniro, M.J. \& Epstein, S. (1981) Influence of diet on the distribution of nitrogen isotopes in animals. Geochimica et Cosmochimica Acta, 45, 341-351.
Ehlinger, T.J. \& Wilson, D.S. (1988) Complex foraging polymorphism in bluegill sunfish. Proceedings of the National Academy of Sciences, 85, 1878-1882.

Fincke, O.M. (1982) Lifetime mating success in a natural population of the damselfly Enallagma hageni Walsh (Odonata: Coenagrionidae). Behavioral Ecology and Sociobiology, 10, 293-302.

Fincke, O.M. (1986a) Lifetime reproductive success and the opportunity for selection in a nonterritorial damselfly (Odonata: Coenagrionidae). Evolution, 40, 791-803.

Fincke, O.M. (1986b) Underwater oviposition in a damselfly (Odonata: Coenagrionidae) favors male vigilance, and multiple mating by females. Behavioral Ecology and Sociobiology, 18, 405-412.

Fincke, O.M. (1987) Female monogamy in the damselfly Ischnura verticalis Say (Zygoptera: Coenagrionidae). Odonatologica, 16, $129-143$

Fincke, O.M. (1994) Female colour polymorphism in damselflies: failure to reject the null hypothesis. Animal Behavior, 47, 1249-1266.

Fincke, O.M. (2004) Polymorphic signals of harassed female odonates and the males that learn them support a novel frequency-dependent model. Animal Behaviour, 66, 833-845.

Fincke, O.M., Jödicke, R., Paulson, D. \& Schultz, D.T. (2005) The evolution and frequency of female color morphs in Holarctic Odonata: why are male-like morphs typically the minority? International Journal of Odonatology, 8, 183-212.

Fincke, O.M., Fargevieille, A. \& Schultz, T.D. (2007) Lack of innate preference for morph and species identity in mate-searching Enallagma damselflies. Behavioral Ecology and Sociobiology, 61, $1121-1131$.

Forbes, M.R.L., Richardson, J.M.L. \& Baker, R.L. (1995) Frequency of female morphs is related to an index of male density in the damselfly Nehalennia irene (Hagen). Ecoscience, 2, 28-33.

Fry, B., Joern, A. \& Parker, P.L. (1978) Grasshopper food web analysis: use of carbon isotope ratios to examine feeding relationships among terrestrial herbivores. Ecology, 59, 498-506.

Grey, J., Kelly, A. \& Jones, R.I. (2004) High intraspecific variability in carbon and nitrogen stable isotope ratios of lake chironomid larvae. Limnology and Oceanography, 49, 239-244.

Hecky, R.E. \& Hesslein, R.H. (1995) Contributions of benthic algae to lake food webs as revealed by stable isotope analysis. Journal of the North American Benthological Society, 14, 631-653.

Hedges, L.V. \& Olkin, I. (1985) Statistical Methods for Meta-analysis. Academic Press, Orlando, Florida.

Herrera, L.G., Korine, M.C., Fleming, T.H. \& Arad, Z. (2008) Dietary implication of intrapopulation variation in nitrogen isotope composition of an old world fruit bat. Journal of Mammalogy, 89, $1184-1190$.

Hutchinson, G.E. (1978) An Introduction to Population Biology. Yale University Press, New Haven, Connecticut.

Jackson, A.L., Inger, R., Parnell, A.C. \& Bearhop, S. (2011) Comparing isotopic niche widths among and within communities: 
SIBER-stable isotope Bayesian ellipses in R. Journal of Animal Ecology, 80, 595-602.

Johnson, R.A. (1986) Intraspecific resource partitioning in the bumble bees Bombus ternaruius and B. pennsylvanicus. Ecology, 87, $133-138$.

Kelly, A., Jones, R.I. \& Grey, J. (2004) Stable isotope analysis provides fresh insights into dietary separation between Chironomus anthracinus and C. plunmosus. Journal of the North American Benthological Society, 23, 287-296.

Layman, C.A., Arrington, D.A., Montana, C.G. \& Post, D.M. (2007) Can stable isotope ratios provide for community-wide measures of trophic structure? Ecology, 88, 42-48.

Layman, C.A., Araujo, M.S., Boucek, R., Hammerschlag-Peyer, C.M., Harrison, E., Jud, Z.R. et al. (2012) Applying stable isotopes to examine food-web structure: an review of analytical tools. Biological Reviews, 87, 545-562.

Lewis, R., O'Connell, T.C., Lewis, M., Campagna, C. \& Hoelzel, A.R. (2006) Sex-specific foraging strategies and resource partitioning in the southern elephant seal (Mirouga leonina). Proceedings of the Royal Society B: Biological Sciences, 273, 2901-2907.

Marrin, D.L. (1983) Ontogenetic changes and intraspecific resource partitioning in the tahoe sucker, Catostomus tahoensis. Environmental Biology of Fishes, 8, 39-47.

Matthews, B. \& Mazumder, A. (2004) A critical evaluation of intrapopulation variation of $\delta^{13} \mathrm{C}$ and isotopic evidence of individual specialization. Oecologia, 140, 361-371.

McCutchan, J.H. Jr, Lewis, W.M. Jr, Kendall, C. \& McGrath, C.C. (2003) Variation in trophic shift for stable isotope ratios of carbon, nitrogen and sulfur. Oikos, 102, 378-390.

Miller, M.N. \& Fincke, O.M. (1999) Cues for mate recognition and the effect of prior experience on mate recognition in Enallagma damselflies. Journal of Insect Behavior, 12, 801-813.

Newsome, S.D., Martinez del Rio, C., Bearhop, S. \& Phillips, D.L. (2007) A niche for isotopic ecology. Frontiers in Ecology and the Environment, 5, 429-436.

Philips, D.L. \& Gregg, J.W. (2003) Source partitioning using stable isotopes: coping with too many sources. Oecologia, 136, 261-269.
Robertson, H.M. (1985) Female dimorphism and mating behaviour in a damselfly, Ischnura ramburi: females mimicking males. Animal Behaviour, 33, 805-809.

Rolff, J. \& Martens, A. (1997) Completing the life cycle: detachment of an aquatic parasite (Arrenurus cuspidator, Hydrachnellae) from an aerial host (Coenagrion puella, Odonata). Canadian Journal of Zoology, 75, 655-659.

Schluter, D. (1993) Adaptive radiation in sticklebacks: size, shape, and habitat use efficiency. Ecology, 74, 699-709.

Sherratt, T.N. (2001) The evolution of female-limited polymorphisms in damselflies: a signal detection model. Ecology Letters, 4, 22-29.

Shine, R., Reed, R.N., Shetty, S. \& Cogger, H.G. (2002) Relationships between sexual dimorphism and niche partitioning within a clade of sea-snakes (Laticaudinae). Oecologia, 133, 45-53.

Smith, B.P. (1988) Host parasite interaction and impact of larval water mites on insects. Annual Review of Entomology, 33, 87-507.

Smith, T.B. (1990) Resource use by bill morphs of an African finch: evidence for intraspecific competition. Ecology, 71, 1246-1257.

Van Gossum, H., Sherratt, T.N. \& Cordero-Rivera, A. (2008) The evolution of sex-limited colour polymorphism. Dragonflies and Damselflies: Model Organisms for Ecological and Evolutionary Research, pp. 219-229. Oxford University Press, Oxford, U.K.

Webb, S.C., Hedges, R.E.M. \& Simpson, S.J. (1998) Diet quality influences the $\delta^{13} \mathrm{C}$ and $\delta^{15} \mathrm{~N}$ of locusts and their biochemical components. Journal of Experimental Biology, 201, 2903-2911.

Westfall, M.J. \& May, M.L. (1996) Damselflies of North America. Scientific Publishers, Gainesville, Florida.

Xu, M. \& Fincke, O.M. (2011) Tests of the harassment-reduction function and frequency-dependent maintenance of a female-specific color polymorphism in a damselfly. Behavioral Ecology and Sociobiology, 65, 1215-1227.

Accepted 14 August 2013

First published online 28 October 2013 